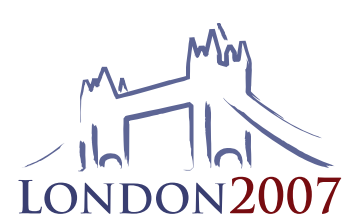

\title{
1004
}

\section{The Results of the Western Frontiers Association} Research Project

D. Long* (British Geological Survey), J. Bulat (British Geological Survey), R. Gatliff (British Geological Survey), R. Holmes (British Geological Survey), A. Leslie (British Geological Survey), D. Mclnroy (British Geological Survey), D. Ritchie (British Geological Survey), A. Stevenson (British Geological Survey), H. Stewart (British Geological Survey), M. Stoker (British Geological Survey) \& C. Wilson (British Geological Survey) 


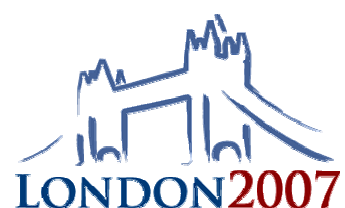

In 1995 most of the operators with interests west of Shetland joined with the British Geological Survey and the Health and Safety Executive to form a Joint Industry Project to look at the shallow geology and geohazards in the area. It was subsequently extended to cover all the deep-water areas north and west of Scotland. The JIP initiated a wide range of studies including assessing slope stability, the risk of methane hydrates, establishing a seismicity monitoring network and developing a detailed model of the stratigraphy for the shallow section throughout the area. The project also acquired new geological and geotechnical data to test the shallow stratigraphy, the age of key events such as the Afen Slide, and supported a major EU research project evaluating the development of the NE Atlantic Neogene Continental Neogene margin. This work has involved the sharing of operator and BGS data to provide an extensive coverage and allowed the production of regional seabed images from the initial returns of 3D exploration data. The establishing of the regional setting has allowed operators and their consultants to evaluate individual site-specific conditions more thoroughly for exploration and development.

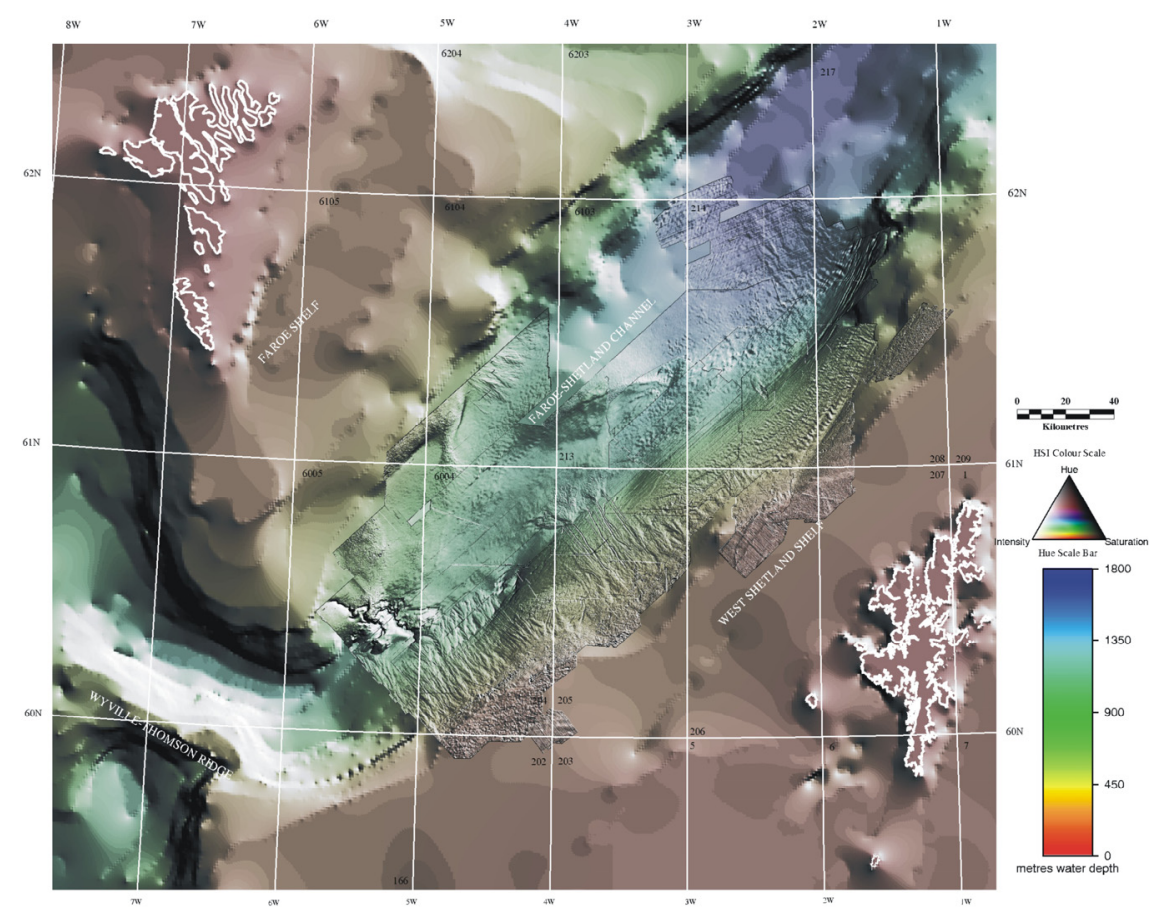

